\title{
Helicobacter pylori infection and dental care
}

P G Hardo, A Tugnait, F Hassan, D A F Lynch, A P West, N P Mapstone, P Quirke, D M Chalmers, M J Kowolik, A T R Axon

\begin{abstract}
Sixty two patients (mean age $45 \cdot 6$ years) were assessed for oral hygiene and periodontal disease by dental examination before endoscopy. Information about oral care, smoking, and dentures was obtained and samples of dental plaque collected. The presence of Helicobacter pylori in plaque as sought by culture and polymerase chain reaction (PCR), and gastric antral biopsy specimens were taken for histological examination. Although $H$ pylori was detected in the antral specimens of 34 patients $(54 \%)$ all of the cultures of dental plaque were negative, and PCR was only positive from the dentures of one patient. Smokers had poor oral hygiene, visited their dentist less often, and brushed their teeth less frequently. There was no correlation of $H$ pylori gastritis with either dental hygiene or periodontal disease. These results suggest that dental plaque or dentures are not an important reservoir for $H$ pylori and are probably not a significant factor in transmission of the organism. The conflicting results in published works may be caused by differences in sample collection, culture techniques, or oral contamination from gastric juice as a result of gastro-oesophageal reflux at the time of endoscopy.

(Gut 1995; 37: 44-46)
\end{abstract}

Keywords: Helicobacter pylori, dental care.

Departments of Gastroenterology P G Hardo F Hassan

D A F Lynch

D M Chalmers

A T R Axon

Periodontology

A Tugnait

M J Kowolik

\section{Microbiology}

A P West

and Pathology

N P Mapstone

P Quirke

Centre for Digestive Diseases, The General Infirmary at Leeds, Leeds

Correspondence to: Dr P G Hardo, Department of Gastroenterology, Centre for Digestive Diseases, The General Infirmary at Leeds, Great George Street, Leeds LS1 3EX.

Accepted for publication 10 November 1994 restorations, provide hard surfaces that known, however, whether their presence increases the risk of infection with $H$ pylori.

The aims of this study were: (a) to confirm previous reports that dental plaque harbours
$H$ pylori, and may act as a reservoir for the organism and (b) to determine the relation between $H$ pylori gastritis and dental health.

\section{Methods}

Subjects

Patients referred to the dyspepsia clinic were asked to participate in the study. Sixty two patients, $26(42 \%)$ women and $36(58 \%)$ men with a mean age 45.6 years (range 20-73), took part. The aim of the study was explained to the patient and written consent obtained. The study was approved by the local ethics committee.

\section{Oral health assessment}

This was done before endoscopy. A detailed history and clinical assessment including information regarding oral care such as, teeth cleaning, number of visits to the dentist in the last 12 months, and dentures were obtained. Oral hygiene was assessed by the simplified oral hygiene index (OHI-S), ${ }^{14}$ on a scale of 0 to 6 $(0-<1=$ good oral hygiene, $1-<2=$ moderately good, $2-<3=$ fair, and 3-6=poor).

A general periodontal assessment was made using the community periodontal index of treatment needs (CPITN). ${ }^{15}$ These data were used to compute a single periodontal status index value for each subject and was scored: (III) moderate periodontitis, for subject with at least one CPITN sextant recording of 4, (II) mild periodontitis, for subject with at least one CPITN sextant recording of 3 but no higher, (I) gingivitis, for subject with at least one CPITN sextant recording of 2 but no higher, (0) for subject with no teeth. This conversion was performed to simplify handling of the periodontal health/disease data.

Dental plaque was sampled at the site with the deepest pocket reading and removed from the clinical site using one sterile paper point. Both subgingival and supragingival plaque (where both present) were sampled. If the patient was a denture wearer then a sample of dental plaque was taken from the impression surface of the denture and placed in the container along side the oral specimen. The plaque sample was placed in a sterile container and immediately immersed in liquid nitrogen to freeze it. Samples were stored in a frozen state until polymerase chain reaction (PCR) testing was performed.

A second dental plaque sample was removed from the same site with a sterile curette. The instrument tip was inserted to the depth of the crevice/pocket and brought up in continuous contact with the tooth surface to sample both 
subgingival and supragingival plaque. The sample was plunged into a liquid transport medium of brain-heart infusion broth and dispersed by agitating the phial. If the patient was a denture wearer then a second sample was removed from the impression surface of the denture and dispersed in a second phial of nutrient broth, which was analysed separately from the oral specimen. The dental plaque samples obtained were sent for culture and PCR amplification of $H$ pylori.

\section{Microbiology}

Dental plaque taken from patients' samples were either centrifuged on arrival for five minutes then cultured, or stored at $-70^{\circ} \mathrm{C}$ and cultured at a later date. Plates were incubated at $37^{\circ} \mathrm{C}$ for two to seven days in a microaerobic atmosphere. Colonies resembling $H$ pylori on VCAT agar $^{16}$ were picked off for Gram staining, oxidase, catalase, and urease tests.

\section{PCR}

All PCR specimens were immediately frozen in individual containers and underwent DNA extraction using a standard proteinase $K$, hexadecyl-trimethyl-ammonium bromide and phenol chloroform method. ${ }^{17}$ The PCR used nested primers specific for the $16 \mathrm{~S}$ ribosomal RNA gene of $H$ pylori. ${ }^{11}$ Each PCR amplification was performed with a further negative control containing water, and a positive control containing $100 \mathrm{fg}$ of $H$ pylori DNA.

\section{Endoscopy}

Endoscopy was performed with an Olympus GIF Q20 gastroscope under intravenous sedation, endoscopic findings were recorded, and two antral biopsy specimens were then taken. Biopsy forceps were sterilised and endoscopes were disinfected between patients using an automatic washing machine (Key MED Autodisinfector-2).

\section{Histological examination}

The two antral biopsy specimens were processed routinely, embedded in paraffin wax, and stained with haematoxylin and eosin

TABLE I Oral care and hygiene findings in all subjects

\begin{tabular}{lc}
\hline & $N o(\%)$ \\
\hline Brushing teeth: times per week & 62 \\
$7-14$ & $33(85 \cdot 5)$ \\
$2-5$ & $8(13 \cdot 9)$ \\
1 & $1(1 \cdot 6)$ \\
Number of visits to the dentist in the last 12 months & 62 \\
2 & $24(38 \cdot 7)$ \\
1 & $6(9 \cdot 7)$ \\
Less often & $32(51 \cdot 6)$ \\
Dentures present & $23(37)$ \\
Oral hygiene index (OHI) of teeth & 53 \\
$0-<1$ (good) & $15(24 \cdot 5)$ \\
$1-<2$ (moderate) & $18(34)$ \\
$2-<3$ (fair) & $15(24 \cdot 5)$ \\
$3-6$ (poor) & $7(17)$ \\
Periodontal status scale (PSI) & 62 \\
III=moderate periodontitis & $3(4 \cdot 8)$ \\
II=mild periodontitis & $16(25 \cdot 8)$ \\
I=gingivitis & $34(45 \cdot 8)$ \\
$0=$ no teeth & $9(14 \cdot 5)$ \\
\hline
\end{tabular}

TABLE II Identification of $\mathrm{H}$ pylori from gastric antrum and dental plaque

\begin{tabular}{lc}
\hline & No $(\%)$ \\
\hline H pylori in antral biopsy specimens & $34 / 62(54)$ \\
$H$ pylori cultured from dental plaque & $0 / 62(0)$ \\
pylori identified from dental plaque (denture) & $1 / 62(1 \cdot 6)$ \\
by PCR &
\end{tabular}

and by the modified Giemsa technique to show the bacteria histologically. Changes of gastritis and $H$ pylori colonisation were classified simply as present or absent.

\section{Statistical methods}

The data were analysed using SPSS for Windows statistical software (release 5.0) Spearman correlation coefficients were calculated and $p$ values of $<0.05$ were regarded as being statistically significant.

\section{Results}

Table I shows the findings of the patients' oral care and hygiene status. Most ( $85.5 \%$ ) patients said they brushed their teeth at least once a day. More than half $(58.5 \%)$ of assessed patients had good to moderate OHI score. A small percentage $(4 \cdot 8 \%)$ had moderate periodontitis. Twenty three (37\%) patients (mean age 54.5 years) had dentures, and none $(14.5)$ were edentulous.

The endoscopic findings were: normal appearance $24(38 \cdot 7 \%)$, duodenal ulcer 11 $(17 \cdot 7 \%)$, oesophagitis $11(17 \cdot 7 \%)$, hiatus hernia $11(17 \cdot 7 \%)$, gastric ulcer $3(4 \cdot 8 \%)$, Barrett's oesophagus $1(1.6 \%)$, and gastric cancer $1(1 \cdot 6 \%)$.

$H$ pylori was detected in antral samples from 34 patients $(54 \%)$ all of whom had gastritis. None of the dental plaque cultures were positive for $H$ pylori. One patient (age 70 ) with $H$ pylori gastritis and a normal endoscopy had a positive PCR on a sample of dental plaque take from denture. All the other samples of dental plaque were negative by PCR (Table II).

Table III shows the correlation between $H$ pylori in gastric antrum, smoking and with gastritis, and measures of dental health. All the antral specimens containing $H$ pylori showed gastritis on histological examination. There was no significant correlation between $H$ pylori gastritis and age, sex, dental hygiene, or periodontal disease. Smokers had higher scores for poor oral hygiene $(p=0.0001)$, and visited their dentist less often $(p=0.001)$. Smoking was not associated with a higher rate of $H$ pylori gastritis.

TABLE III Correlation of $\mathrm{H}$ pylori in gastric antrum and smoking with gastritis and measures of dental health

\begin{tabular}{|c|c|c|c|c|}
\hline & \multicolumn{2}{|c|}{$\begin{array}{l}\mathrm{H} \text { pylori in antral } \\
\text { biopsy specimens }\end{array}$} & \multicolumn{2}{|c|}{$\begin{array}{l}\text { Smoking } \\
\text { (cigarettes/day) }\end{array}$} \\
\hline & $\mathbf{r}$ & $\mathbf{p}$ & $\mathbf{r}$ & $\mathbf{p}$ \\
\hline Antral gastritis & $1 \cdot 0$ & 0.0001 & $0 \cdot 21$ & NS \\
\hline $\begin{array}{l}\text { Time between visits to } \\
\text { dentist } \\
\text { Brushing teeth - times }\end{array}$ & $0 \cdot 18$ & NS & -0.41 & 0.001 \\
\hline $\begin{array}{l}\text { per week } \\
\text { Oral hygiene index }\end{array}$ & -0.03 & NS & -0.29 & 0.03 \\
\hline $\begin{array}{l}0 \text { (good)- } 6 \text { (poor) } \\
\text { Periodontal status scale }\end{array}$ & $\begin{array}{r}0.26 \\
-0.05\end{array}$ & $\begin{array}{l}\text { NS } \\
\text { NS }\end{array}$ & $\begin{array}{l}0.49 \\
0 \cdot 17\end{array}$ & $\begin{array}{l}0.001 \\
\text { NS }\end{array}$ \\
\hline
\end{tabular}




\section{Discussion}

Robson and Moynihan in 1904, suggested that oral sepsis might play a part in the pathogenesis of gastric ulcers. ${ }^{18}$ Recently, attention has been focused on the importance of dental plaque in harbouring $H$ pylori and its role in the epidemiology of $H$ pylori infection. Published works in this field give conflicting results on the incidence of $H$ pylori detected in dental plaque and its significance. Reports from India ${ }^{6}$ and Scotland ${ }^{5}$ on a small number of subjects showed a high prevalence of positive culture in dental plaque. However, successful culture elsewhere is rare..$^{19}$

Others reported negative dental plaque culture but a positive PCR reaction. ${ }^{8}$ PCR is a very sensitive technique but a positive result cannot confirm viability of the bacteria, nor exclude the possibility of bacterial contamination.

Our results with PCR and culture show that $H$ pylori is rarely present in dental plaque in patients with $H$ pylori gastritis or peptic ulcer disease. Our one positive PCR result may be explained by contamination of dentures from gastric juice as a result of gastro-oesophageal reflux.

It is difficult to explain the difference reported in published works between the high and low detection rate of $H$ pylori in dental plaque. This may result from methods of sample collection and culture technique, or oral contamination caused by gastrooesophageal reflux at the time of endoscopy. Future studies should include samples of dental plaque taken before and after endoscopy.

The abnormally high positive results from India may reflect the local standards of dental care and hygiene, eating habits, sanitation practice, and socioeconomic class.

We conclude that dental plaque is not an important reservoir for $H$ pylori in the United Kingdom and cannot be a significant factor in the method of transmission of these bacteria in developed countries.
This work has been published as an abstract in Gut 1993; 34 (suppl 4): F277.

1 Graham DY. Campylobacter pylori and peptic ulcer disease. Gastroenterology 1989; 86 (suppl): 615-25.

2 Forman D, Newell DG, Fullerton F, Yarnell JWG, Ratcey AR, Wald N, et al. Association between infection with Helicobacter pylori and risk of gastric cancer: evidence Helicobacter pylori and risk of gastric cancer: evidence

from a prospective investigation. BMF 1991; 302: 1302-5.
3 Kelein DK, Graham DY, Gaillour A, Opekun RA, Smith EO. Water source as risk factor for Helicobacter pylori EO. Water source as risk factor for Helicobacter pylori
infection in Peruvian children. Lancet 1991; 337: 1503-6.

4 Mai U, Borsch G, Opferkuch W. Route of infection in Campylobacter pylori (CP) disease. Gastroenterology 1989; 96 (suppl 5): 315.

5 Khandaker MAK, Scott A, Eastwood MA, Palmer KR. Do teeth predispose to duodenal ulcer relapse? Gut 1991; 32: A1207.

6 Majmudar P, Shah SM, Dhunjibhoy KR, Desai HG. Isolation of Helicobacter pylori from dental plaques in healthy volunteers. Indian f Gastroenterol 1990; 9: 271-2.

7 Desai HG, Gill K, Shankaran PR, Metha PR, Prabhu SR. Dental plaque: permanent reservoir of Helicobacter Dental plaque: permanent reservoir of Hcand f Gastroenterol 1991; 26: 1205-8.

8 Bantvala N, Lopez CR, Owen R, Abdi Y, Davis G, Hardie $\mathrm{J}$, et al. Helicobacter pylori in dental plaque. Lancet 1993; J, et al. He.

9 Krajden S, Fuska M, Anderson JC, et al. Evidence of Campylobacter pylori in stomach biopsies, saliva, and dental plaque. f Clin Microbiol 1989; 27: 1397-8.

10 Mapstone NP, Lynch D, Lewis AF, Axon ATR, Dixon MF, Quirke $\mathrm{P}$. The polymerase chain reaction in the diagnosis of Helicobacter infection. Ital f Gastroenterol 1991; 23 (suppl): 4.

11 Mapstone NP, Lynch DAF, Lewis AF, Axon ATR, Dixon MF, Quirke P. Identification of Helicobacter infection DNA in the mouths and stomach of patients with gastritis using PCR. F Clin Pathol 1993; 46: 540-3.

12 Tompkin DS, Godwin PGR, West AP, Dixon MF, Sobala GM, Axon ATR. Campylobacter pylori in gastric juice. In: Megaraud F, Lamouliatte H, eds. Gastroduodenal pathology and Campylobacter pylori. Amsterdam: Elsevier pathology and Campylobc

13 Thomas JE, Gibson GR, Darboe M, Dale A, Weaver L. Isolation of Helicobacter pylori from human faeces. Lancet 1992; 340: 1194-5.

14 Greene JC, Vermillian JR. The simplified oral hygiene index. F Am Dent Assoc 1964; 68: 7-13.

15 Ainamo J, Barnes D, Beagrie G, Cutress T, Martin J, SardoInfirri J. Development of the World Health Organization (WHO) Community Periodontal Index of Treatment Needs (CPITN). Int Dental f 1982; 32: 281-91.

16 Tompkins DS, Nehaul BBG, Smith CAF, Cook EM. Evaluation of the phadebact gonococcus test in the identiEvaluation of the phadebact gonococcus test in the identi-
fication of Neisseria gonorrhoea in a routine diagnostic fication of Neisseria gonorrhoea in a routine

17 Ho SA, Hoyle JA, Lewis FA, Secker AD, Cross D, Mapstone NP, et al. Direct polymerase chain reaction test for detection of Helicobacter pylori in humans and animals. F Clin Microbiol 1991; 29: 2543-9.

18 Mayo Robson AW, Moynihan BGA. Diseases of the stomach and their surgical treatment. 2nd ed. London: Bailliere, Tindall and Cox, 1904: 165.

19 Brenandre S, Dalen J, Gastrin B, Hendenborg L, Lamke LO, Ohrn R. Absence of Helicobacter pylori in dental plaque in Helicobacter pylori positive dyspepsia. Eur $\mathcal{F}$ Microbiol Infect Dis 1993; 12: 282-4. 